Supporting Information

\title{
Soft Particles Enable Fast and Selective Water Transport through Graphene Oxide Membranes
}

Wenbin Zhang, ${ }^{\dagger}, *$ Mengqi Shi ${ }^{\dagger}$ Zhongxuan Heng, ${ }^{\dagger}$ Weiming Zhang, ${ }^{\dagger}, * * *$ and Bingcai Pan ${ }^{\dagger, *}$

†State Key Laboratory of Pollution Control and Resource Reuse, School of the Environment, Nanjing University

163 Xianlin Road, Nanjing 210023, China

\$Research Center for Environmental Nanotechnology (ReCENT), Nanjing University

163 Xianlin Road, Nanjing 210023, China.

E-mail: wmzhang@nju.edu.cn (Weiming Zhang)

wbzhang2009@sinano.ac.cn (Wenbin Zhang) 


\section{Table of Contents}

\section{Experimental Procedures}

Materials

Fabrication of the GO membranes intercalated with soft PAN GPs

Characterizations

Theoretical calculations

Heavy metal-organic complex separation tests

The durability experiments

Results and Discussion

Figure S1 The sizes of PAN GPs determined by DLS in mixed suspensions with different EtOH vol. $\%$

Figure S2 AFM characterizations of GO sheets on a mica wafer

Figure S3 AFM surfacial images of the pristine GOM, TPP@GOM-30, and ATPP@GOM-n (n=20, $30,50,70)$ membranes

Figure S4 Photos and SEM images of GOM, TPP@GOM-30, and ATPP@GOM-30 membranes

Figure S5 XRD patterns and the interlayer distances of GOM, TPP@GOM-30, and ATPP@GOM30 membranes

Figure S6 C1s narrow scan spectra of the TPP@GOM-30 and ATPP@GOM-30 membranes

Figure S7 FTIR spectra of the pristine GOM, TPP@GOM-30, and ATPP@GOM-30 membranes

Figure S8 Shake-up peaks in C1s narrow scan spectra of the alkalized GOM and ATPP@GOM-30

Figure S9 Surface zeta potentials of the pristine GOM, TPP@GOM-30, and ATPP@GOM-30 membranes

Figure S10 Water contact angles of the TPP@GOM-30, and ATPP@GOM-30 membranes

Figure S11 Geometric structures and size distributions of $\mathrm{Cu}_{-} \mathrm{EDTA}^{2-}, \mathrm{Cu}-\mathrm{CA}^{-}, \mathrm{Cu}-\mathrm{NTA}^{-}, \mathrm{Ni}-$ EDTA $^{2-}$ and Cr-EDTA ${ }^{-}$

Figure S12 The flux and recovery rate of ATPP@GOM-30 in response to different pressure

Figure S13 The rejections of ATPP@GOM-30 for low concentration of Cu-EDTA in solution

Figure S14 Photos and SEM analyses for the GO membranes after cycles of filtration tests

Table S1 The element contents of the pristine GOM, TPP@GOM-30, and ATPP@GOM-30 membranes 
Table S2 The root mean square roughness of pristine GOM, TPP@GOM-30 and ATPP@GOM-n $(\mathrm{n}=20,30,50,70)$ membranes

Table S3 Surface chemical compositions of the TPP@GOM-30 and ATPP@GOM-30 membranes

Table S4 Rejections for various metal ions of the ATPP@GOM-30 membranes

Table S5 Heavy metal-organic complex species and their percentages in the corresponding solutions

Table S6 The collision dimensions of main heavy metal-organic complexes present in the corresponding solutions

\section{References}




\section{Experimental Procedures}

Materials. Graphene oxide (GO) sheets were obtained from Hangzhou Gaoxi Tech. Co., Ltd. (Hangzhou, China). PAN powder $(\mathrm{Mw} \approx 150,000)$ was obtained from Shanghai Macklin Biochemical Co., Ltd. (Shanghai, China). Hydrophilic PVDF substrate films ( $25 \mathrm{~mm}$ in diameter, $0.22 \mu \mathrm{m}$ pore size) were obtained from Haiyan New Oriental Plastic Tech. Co., Ltd. (Jiaxing, China). All chemical reagents were of analytical grade and used as received.

Fabrication of the GO membranes with biomimetic water channels. First, $5 \mathrm{mg}$ GO was dispersed into $500 \mathrm{~mL}$ deionized (DI) water through vigorous stirring and ultrasonication to obtain a light brown transparent homogeneous dispersion. Second, a volume of EtOH was added into a PAN/DMF solution $\left(0.5 \mathrm{~g} \mathrm{~L}^{-1}\right)$ to form a uniformly dispersed PAN GPs suspension via continuous stirring at $80{ }^{\circ} \mathrm{C}$ for $12 \mathrm{~h}$; the vol.\% of EtOH in the resulting suspensions was determined to be $20 \%, 30 \%, 40 \%, 50 \%$, and $70 \%$. Subsequently, GO dispersion was introduced into the PAN/(DMF-EtOH) solution through ultrasonication and the GO/PAN mass ratio was controlled to be 1:0.02, 1:0.05, 1:0.1, and 1:0.2, respectively. Finally, the resulting GO membranes were acquired through vacuum filtration of the mixed dispersions of GO and PAN GPs through a hydrophilic PVDF film (pore size: $0.22 \mu \mathrm{m}$ ) and alkaline treatment in a $\mathrm{KOH}$ solution. Typically, $1 \mathrm{ml} \mathrm{GO} / \mathrm{PAN}$ mixed dispersion was added into the top tube above the PVDF film in a glass suction flask to perform infiltration driven by its own weight. Afterwards, $9 \mathrm{~mL}$ dispersion was added and filtrated using a vacuum pump (1 bar) to form a GO hybrid membrane on a PVDF film (TPP@GOM-n). Then, ATPP@GOM-n was obtained after sequential alkaline treatment in a $\mathrm{KOH}$ aqueous solution $(0.5,1,3 \mathrm{wt} \%)$ at $70{ }^{\circ} \mathrm{C}$ for $10 \mathrm{~h}$, rinsing with DI water and thermal treatment at $90{ }^{\circ} \mathrm{C}$ for $1.5 \mathrm{~h}$. In comparison, TPP@GOM-n and pristine GO membranes were prepared.

Characterizations. Malvern Zen 3600 was performed for the DLS measurements of PAN GPs dispersions. SEM images were obtained by an environmental scanning electron microscope (FEI Quanta-FEG 250) with energy-dispersive X-ray spectroscopy for the elemental analysis. Transmission electron microscopy (FEI, Tecnai F20) was performed for the TEM characterization of the GO-based membranes. Height profile measurement of single-layered GO sheets and surface roughness characterization of the GO-based membranes were conducted using a Bruker MultiMode 8 AFM system. The XRD patterns were recorded on a Thermo ARL X'TRA X-ray diffraction at a scan rate of $4^{\circ} / \mathrm{min}$, and the interlayer distance of the membranes was obtained using Bragg's Equation 1 as follows:

$$
d=\frac{\lambda}{2 \sin \theta}
$$

where $d$ is the interlayer distance of the GO membranes, $\lambda$ is the X-ray radiation wavelength, and $\theta$ is the diffraction angle. The FTIR spectra of the membranes were measured on an attenuated total reflectance Fourier transform infrared spectroscopy (Thermo Scientific Nicolet iS5). XPS (ULVAC-PHI MultiPak X-ray photoelectric spectroscopy) was used to ascertain the elemental composition and chemical bonds of the GO-based membranes. The water contact angles were acquired from a Krüss DSA100 instrument. The zeta potential measurement was performed on an Anton Paar SurPASS zeta potential analyzer, and the $\mathrm{pH}$ values was carefully adjusted by $10 \mathrm{mM} \mathrm{HCl}$ and $10 \mathrm{mM} \mathrm{NaOH}$.

Theoretical calculations. The geometric structures of the heavy metal-organic complexes were optimized by the density functional theory (DFT) method using the B3LYP/6-31+G(d) functional and LANL2DZ for metal ions. ${ }^{1}$ The size distributions of heavy metal-organic complexes were determined by Chemcraft software based on the optimized geometries. The 
charges and percentages of all possible chemical species in aqueous solutions at $\mathrm{pH} 7.0$ were acquired using the Visual MINTEQ software (ver.3.0, USA).

Heavy metal-organic complex removal tests. Five heavy metal-organic complex anion solutions (Cu-EDTA, Cu-CA, Cu-NTA, Ni-EDTA, and Cr-EDTA) with the metal concentration of $0.5,1$, and $10 \mathrm{mg} \mathrm{L}^{-1}$ were prepared and carefully adjusted to $\mathrm{pH}=7.0$. The removal tests were performed in a dead-end filtration system with an effective separation area of $2.01 \mathrm{~cm}^{2}$ at room temperature. The transmembrane pressure was controlled to $1 \mathrm{bar}$. To further evaluate the separation performance, a higher pressure ( 2 bar and 3 bar) was also used. The filtrate was carefully collected after permeation, and the water permeance and rejection were acquired according to Equations 2 and 3.

$$
J=\frac{\Delta V}{A \cdot t \cdot \Delta P}
$$

where $J$ is the permeance, $\Delta V$ is the volume of the filtrate collected after a predetermined time, $A$ is the effective area of the membrane, $t$ is the testing time, and $\Delta P$ is the transmembrane pressure.

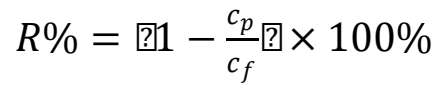

where $\mathrm{R} \%$ is the rejection, $c_{p}$ and $c_{f}$ are the ion concentrations in the filtrate and the feed, respectively, which are determined using inductively coupled plasma spectrometry.

Three metal cations $\left(\mathrm{Cu}^{2+}, \mathrm{Cr}^{3+}, \mathrm{Ni}^{2+}\right)$ were also separated by the ATPP@GOM-30 membranes. In order to eliminate the influence of the adsorption for the cations on the membranes, $100 \mathrm{mg} \mathrm{L}^{-1}$ metal solutions were first filtrated through the GO membranes and the concentration in the filtrate no longer changed $(>20 \mathrm{~h})$. After that, $10 \mathrm{mg} \mathrm{L}^{-1}$ metal solution was filtrated and the filtrate was carefully collected to determine the concentration of metal in the filtrate through Equation 3.

The durability experiments. The GO membrane was sealed by the tape with a hole in the middle to avoid the direct touch of the membrane with the test equipment. After that, the GO membrane combined with the tape was put into an ultrafiltration cup for the separation of heavy metal-organic complex, e.g., Cu-EDTA. The filtration lasted for 24 hours under 1 bar. After that, the GO membrane was taken out and immersed in DI water for another 12 hours. This is one cycle and 7 cycles were performed. 


\section{Results and Discussion}
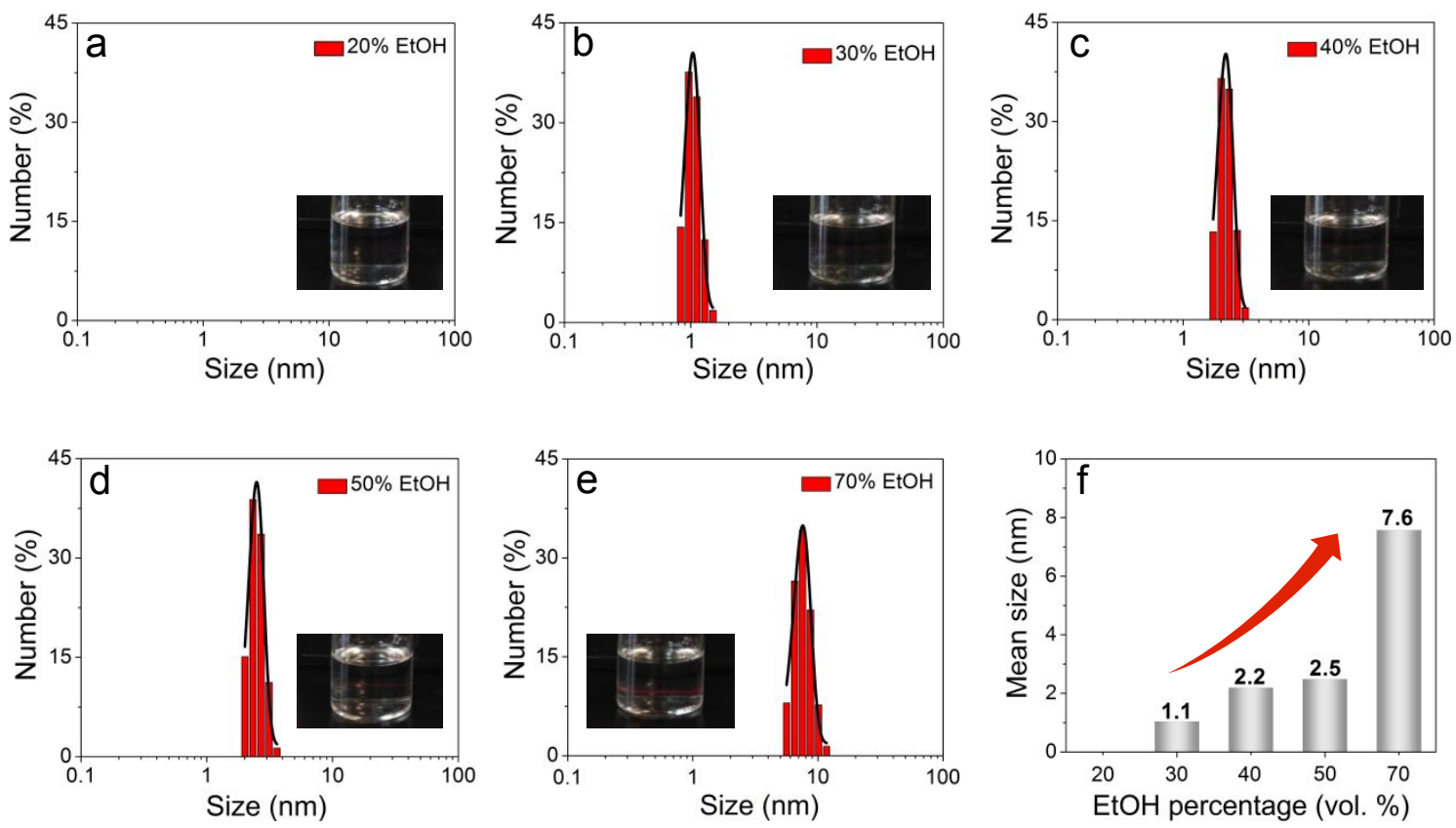

Figure S1. The sizes of PAN GPs determined by DLS in mixed suspensions with different EtOH vol.\%, (a) $20 \%$, (b) $30 \%$, (c) $40 \%$, (d) $50 \%$, and (e) $70 \%$. The insets are optical photographs of the corresponding suspensions, showing the Faraday-Tyndall effect induced by a red laser beam (wavelength: $650 \mathrm{~nm}$ ). (f) The mean sizes of PAN GPs formed with different EtOH percentages.

As the volume percentage (vol.\%) of EtOH in the resulting suspensions was $20 \%$, no Faraday-Tyndall effect or PAN GPs were detected. However, Faraday-Tyndall effect was markedly observed when the EtOH vol.\% was increased to more than $30 \%$, and the sizes of PAN GPs gradually increased to 1.1, 2.2, 2.5, and $7.6 \mathrm{~nm}$ when EtOH vol.\% was controlled to be $30 \%, 40 \%, 50 \%$ and $70 \%$.
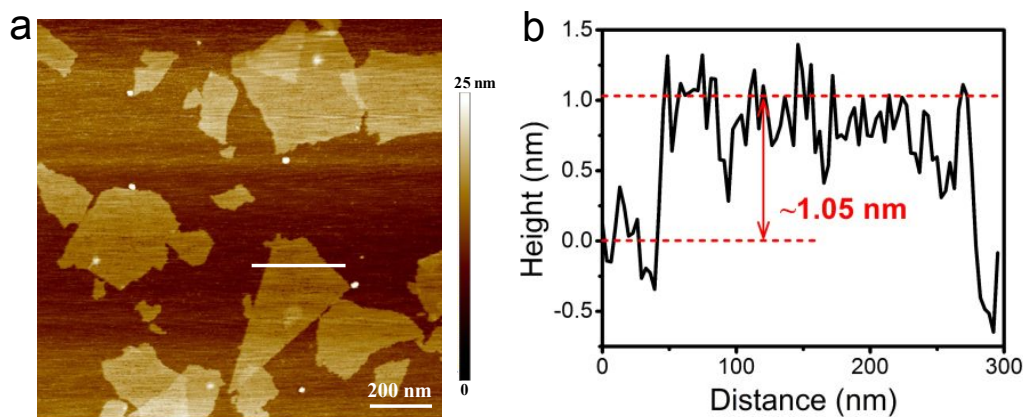

Figure S2. (a) AFM image of the obtained GO sheets on a mica wafer. (b) Height profile of a sheet in (a), showing a lateral size $200 \sim 500 \mathrm{~nm}$ and a thickness $\sim 1.05 \mathrm{~nm}$. 
The element contents determined using XPS in the pristine GO membrane (GOM), TPP@GOM-30, ATPP@GOM-30 membranes are summarized in Table S1. Herein, N element $(\sim 3.77 \%)$ detected in pristine GOM had been possibly produced in the preparation process of GO nanosheets. The lower N contents in ATPP@GOM-30 ( 4.09\%) than TPP@GOM-30 $(\sim 4.21 \%)$ was attributed to the conversion of a partial $-\mathrm{CN}$ groups on PAN GPs to $-\mathrm{COO}^{-}$ groups upon alkaline treatment.

Table S1. The element contents of the pristine GOM, TPP@GOM-30, and ATPP@GOM-30 membranes. (at.\%)

\begin{tabular}{clllc}
\hline Samples & $\mathrm{C}, \%$ & $\mathrm{O}, \%$ & $\mathrm{~N}, \%$ & $\mathrm{~K}, \%$ \\
\hline Pristine GOM & 71.54 & 24.69 & 3.77 & - \\
TPP@GOM-30 & 72.44 & 25.35 & 4.21 & - \\
ATPP@GOM-30 & 73.12 & 22.64 & 4.09 & 0.15 \\
\hline
\end{tabular}

a
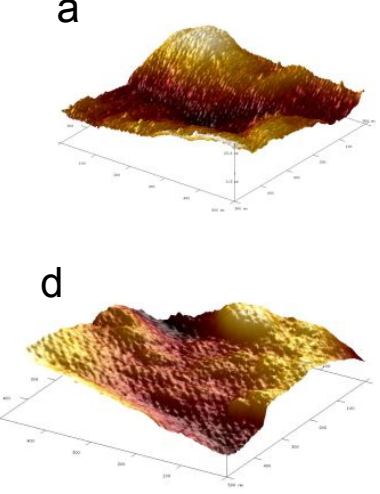

b

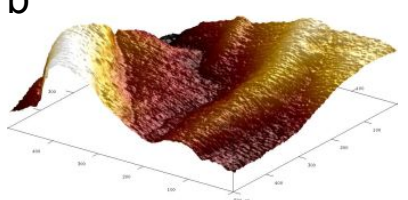

e

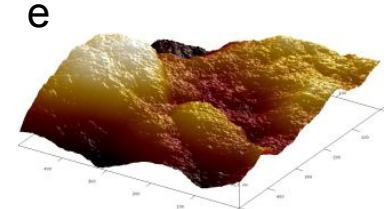

C

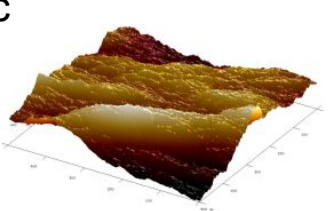

$f$

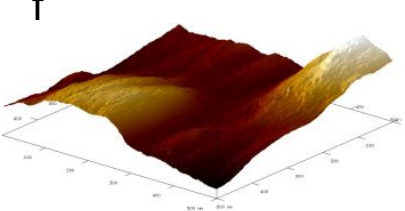

Figure S3. AFM surficial images of (a) pristine GO membranes (GOM), (b) TPP@GOM-30 membranes, (c) ATPP@GOM-20 membranes, (d) ATPP@GOM-30 membranes, (e) ATPP@GOM-50 membranes, (f) ATPP@GOM-70 membranes.

Table S2. The root mean square roughness of control GO membranes fabricated under different conditions.

\begin{tabular}{cc}
\hline Samples & Root mean square roughness $(\mathrm{nm})$ \\
\hline Pristine GOM & $11.1 \pm 0.1$ \\
TPP@GOM-30 & $16.1 \pm 0.7$ \\
ATPP@GOM-20 & $13.6 \pm 0.7$ \\
ATPP@GOM-30 & $21.3 \pm 0.1$ \\
ATPP@GOM-50 & $23.9 \pm 0.6$ \\
ATPP@GOM-70 & $25.9 \pm 0.2$ \\
\hline
\end{tabular}



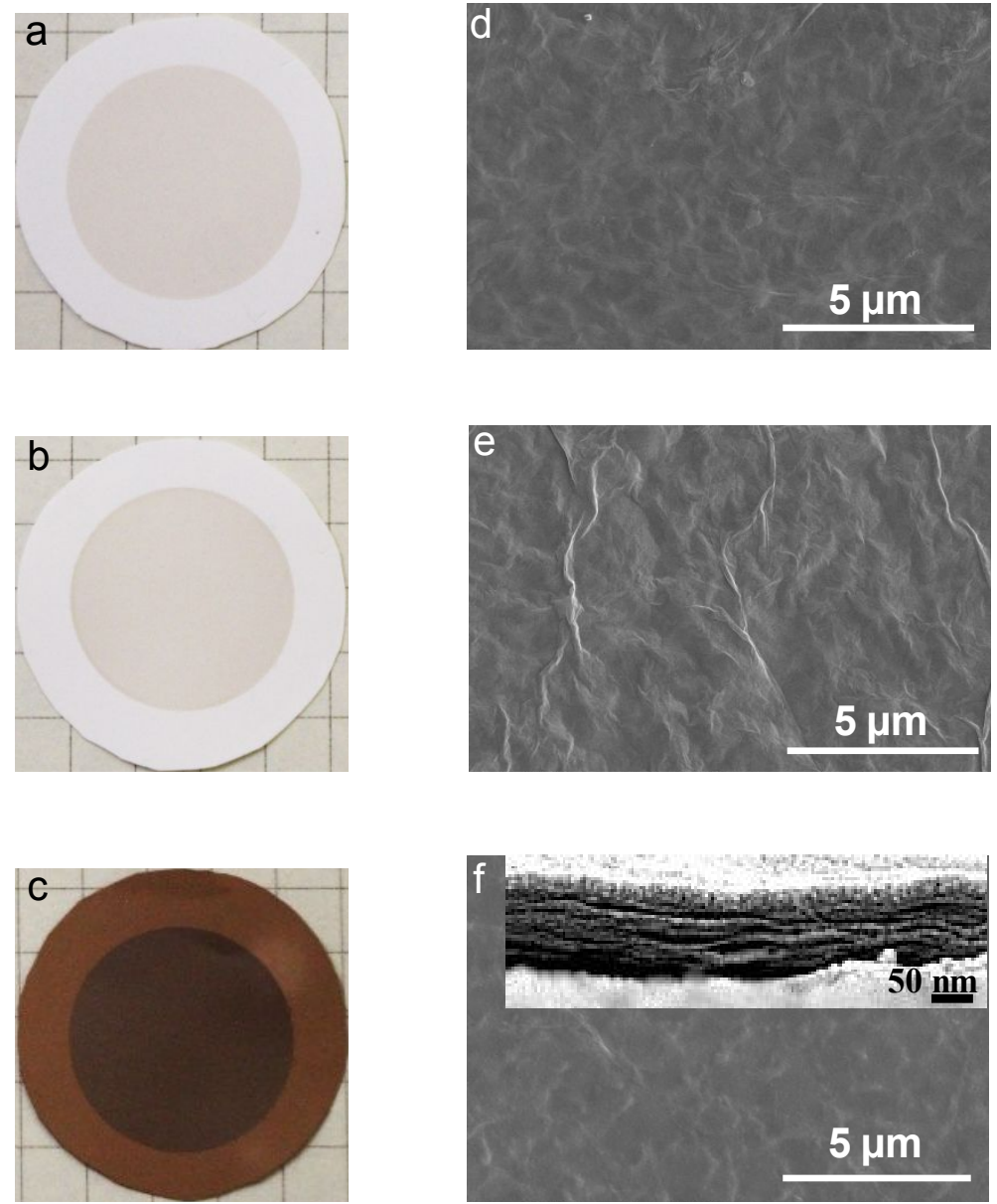

Figure S4. Photographs and SEM images of the pristine GO membrane (a, d), TPP@GOM-30 $(\mathbf{b}, \mathbf{e})$, and ATPP@GOM-30 (c, f) membranes. The inset in (f) is the cross-sectional SEM image of the ATPP@GOM-30 membrane.
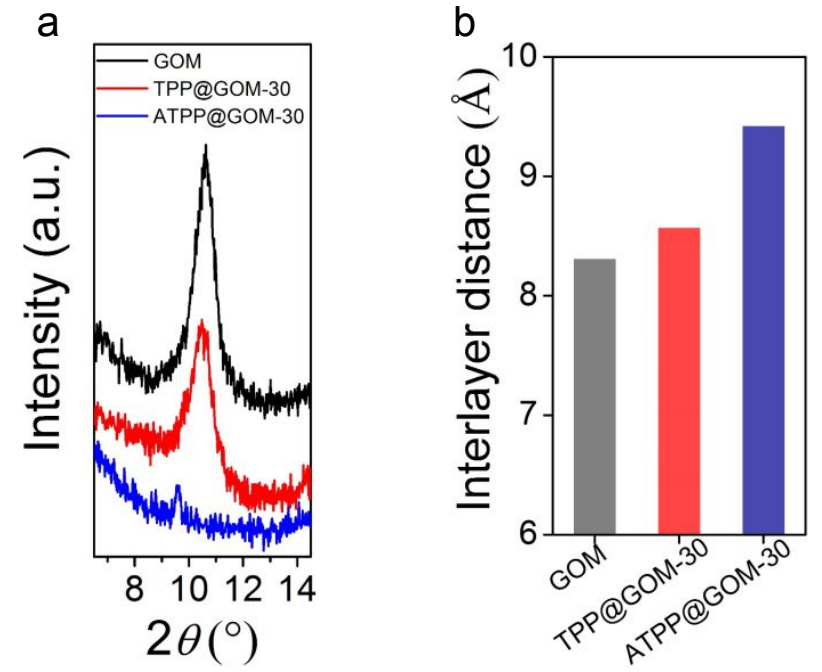

Figure S5. XRD patterns (a) and interlayer distances (b) of the pristine GO membrane (GOM), TPP@GOM-30, and ATPP@GOM-30 membranes. 


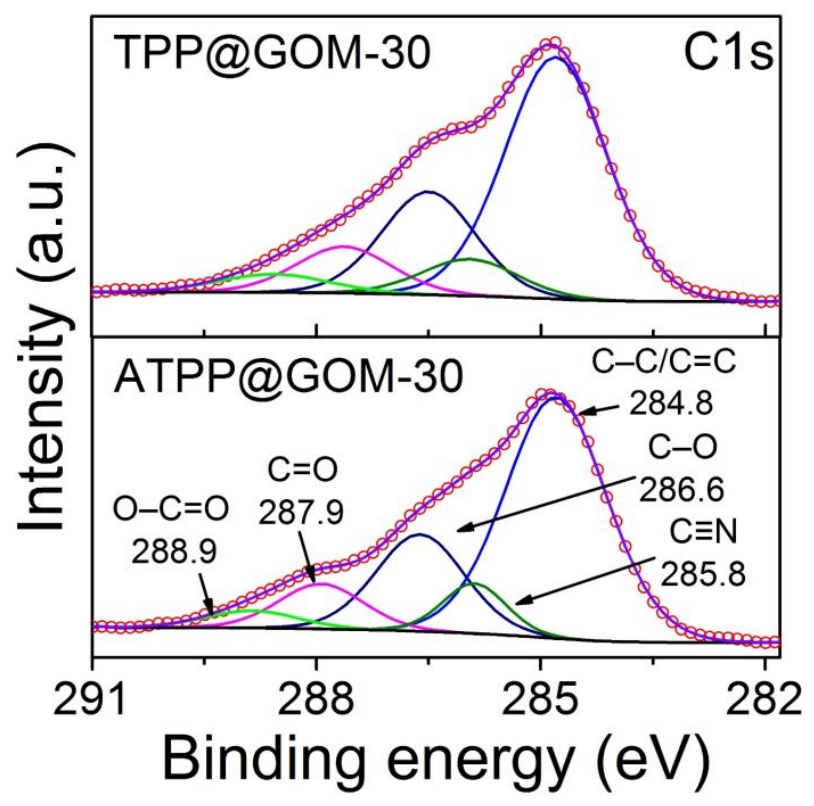

Figure S6. Deconvolution of C1s narrow-scan spectra measured on the TPP@GOM-30 and ATPP@GOM-30 membranes.

Table S3. Surface chemical compositions of the TPP@GOM-30 and ATPP@GOM-30 membranes (at.\%)

\begin{tabular}{lcclll}
\hline \multicolumn{1}{c}{ Samples } & $\mathrm{C}-\mathrm{C} / \mathrm{C}=\mathrm{C}$ & $\mathrm{C} \equiv \mathrm{N}$ & $\mathrm{C}-\mathrm{O}$ & $\mathrm{C}=\mathrm{O}$ & $\mathrm{O}=\mathrm{C}-\mathrm{O}$ \\
\hline TPP@GOM-30 & 55.88 & 7.92 & 21.40 & 11.57 & 3.24 \\
ATPP@GOM-30 & 58.78 & 7.63 & 20.61 & 9.16 & 3.82 \\
\hline
\end{tabular}




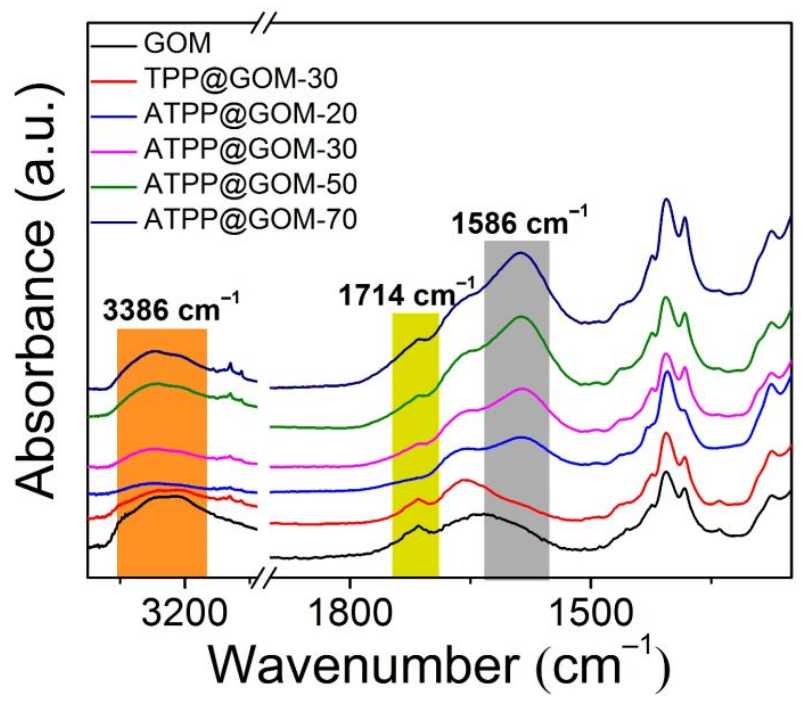

Figure S7. FTIR spectra of the pristine GO membrane (GOM), TPP@GOM-30, and ATPP@GOM-n $(\mathrm{n}=20,30,50,70)$ membranes.

Compared to the pristine GOM and TPP@GOM-30 membranes, the peak $(\mathrm{C}=\mathrm{O})$ at 1714 $\mathrm{cm}^{-1}$ of the ATPP@GOM-n membranes became markedly weaker. Meanwhile, a new peak $\left(-\mathrm{COO}^{-}\right)$at $1586 \mathrm{~cm}^{-1}$ appeared and became gradually stronger with the increase in "n", which suggested that a proportion of $-\mathrm{COOH}$ groups on the $\mathrm{GO}$ sheets and $-\mathrm{C} \equiv \mathrm{N}$ groups on PAN GPs converted into $-\mathrm{COO}^{-}$groups under alkaline conditions. ${ }^{2,3}$ Here, ATPP@GOM-n membranes were obtained with the alkaline treatment in a $1 \% \mathrm{KOH}$ aqueous solution at $70{ }^{\circ} \mathrm{C}$ for $10 \mathrm{~h}$. Meanwhile, the peak $(-\mathrm{OH})$ at $3386 \mathrm{~cm}^{-1}$ first weakened and subsequently strengthened in the ATPP@GOM-n membranes compared to the TPP@GOM-30 membrane, which implies a possible reduction of GO sheets upon the alkaline treatment.
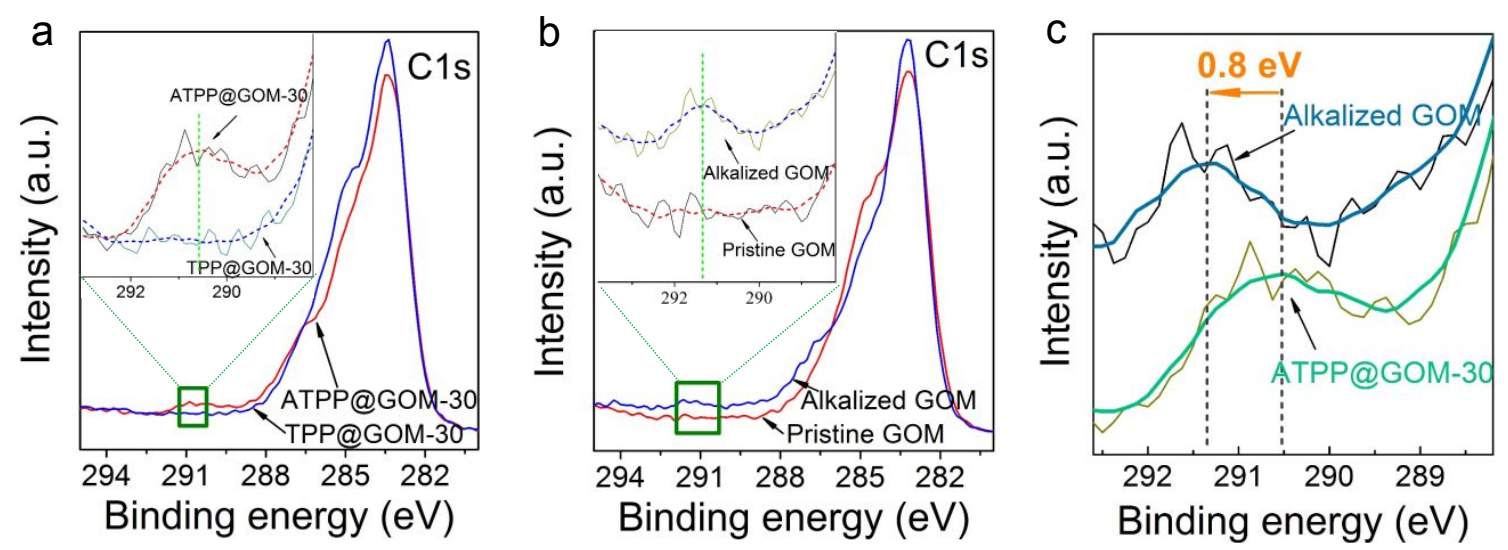

Figure S8. (a) A shake-up peak at $290.6 \mathrm{eV}$ newly detected in the $\mathrm{C} 1 \mathrm{~s}$ narrow scan spectrum of ATPP@GOM-30 membrane, showing the possible reduction of oxygen-containing functional groups on GO sheets during alkaline treatment. (b) A similar shake-up peak at 291.4 eV observed in the alkalized GO membrane. (c) The comparison of the shake-up peaks of the alkalized GO membrane (GOM) and ATPP@GOM-30 membranes. 


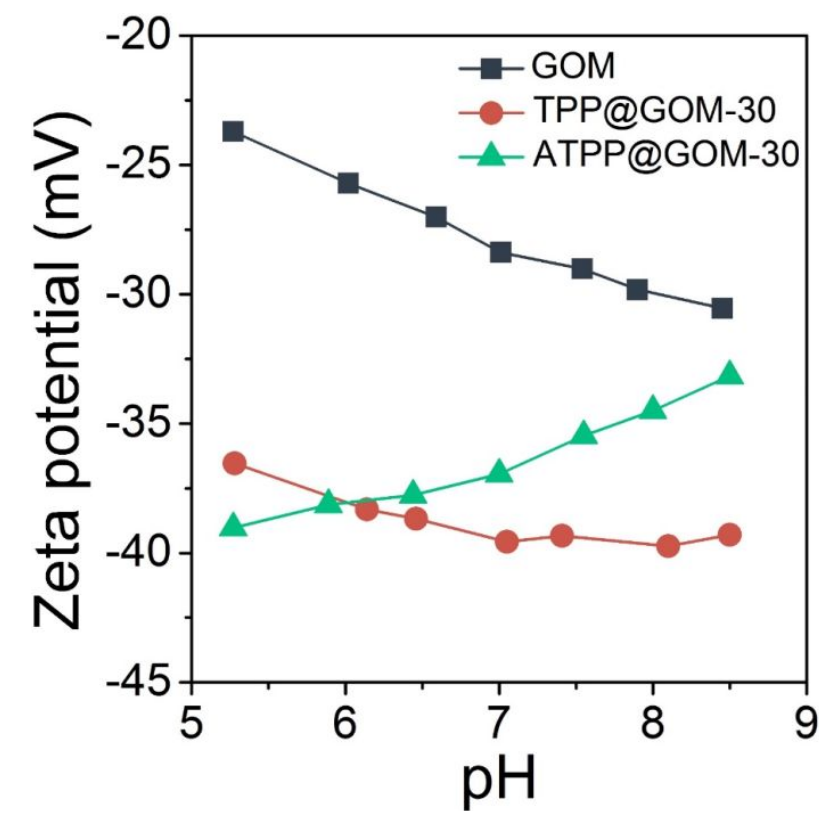

Figure S9. Surface zeta potentials of the pristine GO membrane (GOM), TPP@GOM-30, and ATPP@GOM-30 membranes.

The rejections for heavy metal-organic complexes are higher than their cation counterparts of similar sizes, which suggests Donnan exclusion played an additional role in the separation of complex anions.

Table S4. Rejections for various metal ions of the ATPP@GOM-30 membranes.

\begin{tabular}{ccccccc}
\hline & \multicolumn{3}{c}{ Cations $\left(10 \mathrm{mg} \mathrm{L}^{-1}\right)$} & \multicolumn{3}{c}{ Anions (Metal conc.:10 $\left.\mathrm{mg} \mathrm{L}^{-1}\right)^{\mathrm{a}]}$} \\
\hline Ion & $\mathrm{Cu}^{2+}$ & $\mathrm{Ni}^{2+}$ & $\mathrm{Cr}^{3+}$ & Cu-EDTA & Ni-EDTA & Cr-EDTA \\
Size $(\AA)$ & 8.38 & 8.08 & 9.22 & 8.3 & 8.1 & 8.3 \\
Rejection $(\%)$ & $91.2 \pm 2.1$ & $88.2 \pm 2.5$ & $87.5 \pm 4.7$ & $97.3 \pm 1.5$ & $96.4 \pm 0.4$ & $98.9 \pm 0.1$ \\
\hline
\end{tabular}

[a] Here, the sizes of the anions were obtained using DFT calculations, see Table S6 for details. 


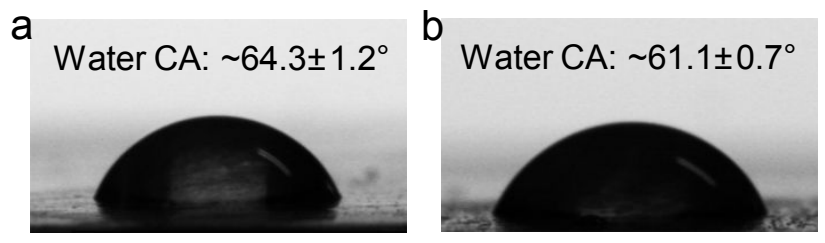

Figure S10. Water contact angles of the (a) TPP@GOM-30 and (b) ATPP@GOM-30 membranes.
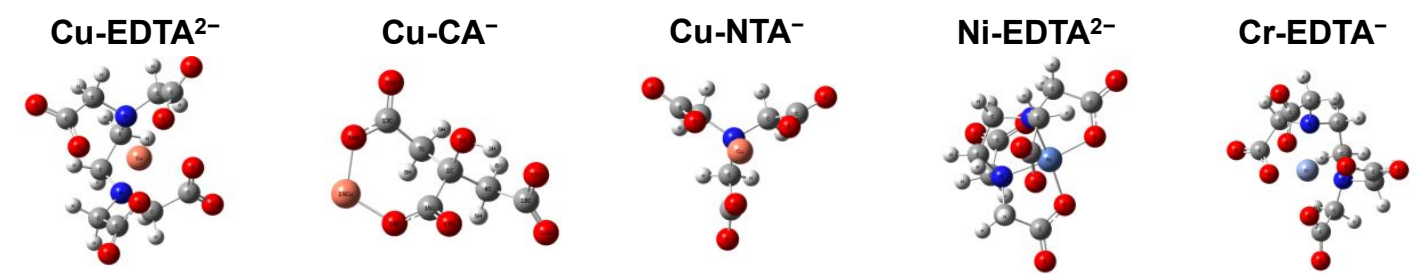

$9.3 \times 8.2 \times 7.5(\AA) \quad 9.5 \times 7.5 \times 5.7(\AA) \quad 7.5 \times 7.5 \times 7.5(\AA) \quad 9.0 \times 7.9 \times 7.5(\AA) \quad 9.6 \times 8.0 \times 7.4(\AA)$

Figure S11. Geometric structures and size distributions of $\mathrm{Cu}-\mathrm{EDTA}^{2-}, \mathrm{Cu}-\mathrm{CA}^{-}, \mathrm{Cu}-\mathrm{NTA}^{-}$, $\mathrm{Ni}^{-E_{D T A}}{ }^{2-}$, and Cr-EDTA ${ }^{-}$, which are the main species in the corresponding $\mathrm{Cu}-\mathrm{EDTA}, \mathrm{Cu}-$ CA, Cu-NTA, Ni-EDTA and Cr-EDTA solutions. All the data were obtained using DFT calculations. 
For heavy metal-organic complex aqueous solutions of $\mathrm{Cu}$-EDTA, $\mathrm{Cu}-\mathrm{CA}, \mathrm{Cu}-\mathrm{NTA}$, NiEDTA and Cr-EDTA (Metal concentration: $10 \mathrm{mg} \mathrm{L}^{-1}$ ), all possible species were determined using Visual MINTEQ software (ver.3.0, USA) at $\mathrm{pH}=7.0 .{ }^{4}$ The calculation results revealed that almost all species bore negative charges, except a small quantity of positively charged ions $\left(\mathrm{Cu}^{2+}: \sim 1.33 \%, \mathrm{CuOH}^{+}: \sim 0.41 \%\right)$ in $\mathrm{Cu}-\mathrm{CA}$ solution.

Table S5. Possible heavy metal-organic complex species and their percentages in the corresponding solutions.

\begin{tabular}{|c|c|c|}
\hline Samples & Species & Percentage, $\%$ \\
\hline \multirow{2}{*}{$\mathrm{Cu}$-EDTA } & $\mathrm{Cu}^{-E_{D T A}{ }^{2-}}$ & 99.97 \\
\hline & Cu-HEDTA ${ }^{-}$ & 0.03 \\
\hline \multirow{2}{*}{$\mathrm{Cu}-\mathrm{NTA}$} & $\mathrm{Cu}-\mathrm{NTA}^{-}$ & 99.73 \\
\hline & $\mathrm{Cu}-\mathrm{OHNTA}{ }^{2-}$ & 0.24 \\
\hline \multirow{5}{*}{$\mathrm{Cu}-\mathrm{CA}$} & Cu-Citrate ${ }^{-}$ & 96.48 \\
\hline & $\mathrm{Cu}^{2+}$ & 1.33 \\
\hline & $\mathrm{Cu}_{2}-(\text { Citrate })_{2}{ }^{2-}$ & 0.86 \\
\hline & $\mathrm{CuOH}^{+}$ & 0.41 \\
\hline & $\mathrm{Cu}-\mathrm{HCitrate}{ }^{-}$ & 0.03 \\
\hline \multirow{2}{*}{ Ni-EDTA } & $\mathrm{Ni}^{-E D T A}{ }^{2-}$ & 99.97 \\
\hline & $\mathrm{Ni}^{\mathrm{NHEDTA}}{ }^{-}$ & 0.03 \\
\hline \multirow{2}{*}{ Cr-EDTA } & $\mathrm{Cr}^{-E_{D T A}}{ }^{-}$ & 85.83 \\
\hline & Cr-OHEDTA ${ }^{2-}$ & 14.17 \\
\hline
\end{tabular}

Table S6. The collision dimensions of main heavy metal-organic complexes present in their corresponding solutions, which were acquired based on DFT calculations. ${ }^{5}$

\begin{tabular}{llc}
\hline \multicolumn{1}{c}{ Species } & \multicolumn{2}{c}{ Collision dimension $(\AA \times \AA \times \AA)^{[\mathrm{a}]}$} \\
& \multicolumn{1}{c}{1 bar } & \multicolumn{1}{c}{ bar } \\
\hline Cu-EDTA $^{2-}$ & $9.3 \times 8.2 \times 7.5(8.3)$ & $9.3 \times 8.7 \times 7.2(8.3)$ \\
Cu-NTA $^{-}$ & $7.5 \times 7.5 \times 7.5(7.5)$ & - \\
Cu-Citrate $^{-}$ & $9.5 \times 7.5 \times 5.7(7.4)$ & $9.5 \times 7.5 \times 5.7(7.4)$ \\
Cu$_{2}$-Citrate $_{2}{ }^{2-}$ & $13.0 \times 8.9 \times 6.8(9.2)$ & $13.1 \times 8.9 \times 6.4(9.0)$ \\
Ni-EDTA $^{2-}$ & $9.0 \times 7.9 \times 7.5(8.1)$ & $9.0 \times 7.9 \times 7.5(8.1)$ \\
Cr-EDTA $^{-}$ & $9.6 \times 8.0 \times 7.4(8.3)$ & $9.6 \times 8.0 \times 7.4(8.3)$ \\
\hline
\end{tabular}

[a] The data in parenthesis are the mean sizes of corresponding heavy metal complex anions. 
The water permeance of Cu-EDTA solution (Metal concentration: $10 \mathrm{mg} \mathrm{L}^{-1}$ ) through the ATPP@GOM-30 membranes under different pressures $(1,2$, and 3 bar) was measured in an ultrafiltration cup. Under each pressure, the filtration lasted for $24 \mathrm{~h}$ and the permeance was measured every 6 hours. Then the GO membrane was taken out and immersed into DI water for one night $(\sim 12 \mathrm{~h})$. After that, the water permeance was measured again in a similar procedure. As shown in Figure s12, all water permeance of the GO membranes demonstrates a $\sim 100 \%$ recovery after immersing in water for one night. Interestingly, the water permeance under high pressure is relatively higher than that under low pressure. For example, the water permeance at 3 bar is $\sim 17.2 \mathrm{~L} \mathrm{~m}^{-2} \mathrm{~h}^{-1}$ bar $^{-1}$, larger than $\sim 15.2 \mathrm{~L} \mathrm{~m}^{-2} \mathrm{~h}^{-1} \mathrm{bar}^{-1}$ at 1 bar.

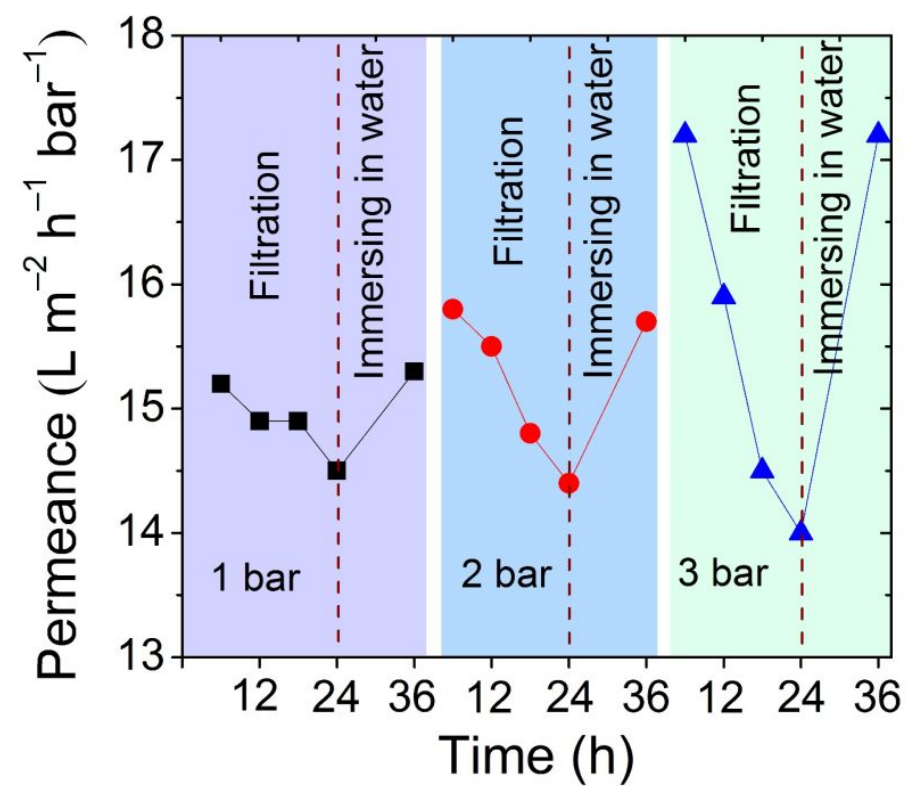

Figure S12. The water permeance of the ATPP@GOM-30 membranes under different pressures.

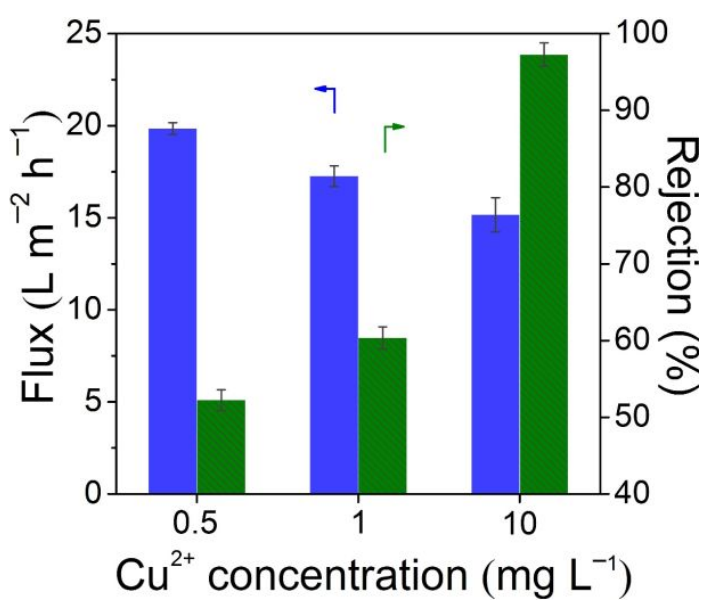

Figure S13. The rejections for different concentrations $\left(0.5,1\right.$, and $\left.10 \mathrm{mg} \mathrm{L}^{-1}\right)$ of $\mathrm{Cu}$-EDTA of the ATPP@GOM-30 membranes. (Applied pressure: 1 bar; the values are mean: SD $(n=3)$ ) 

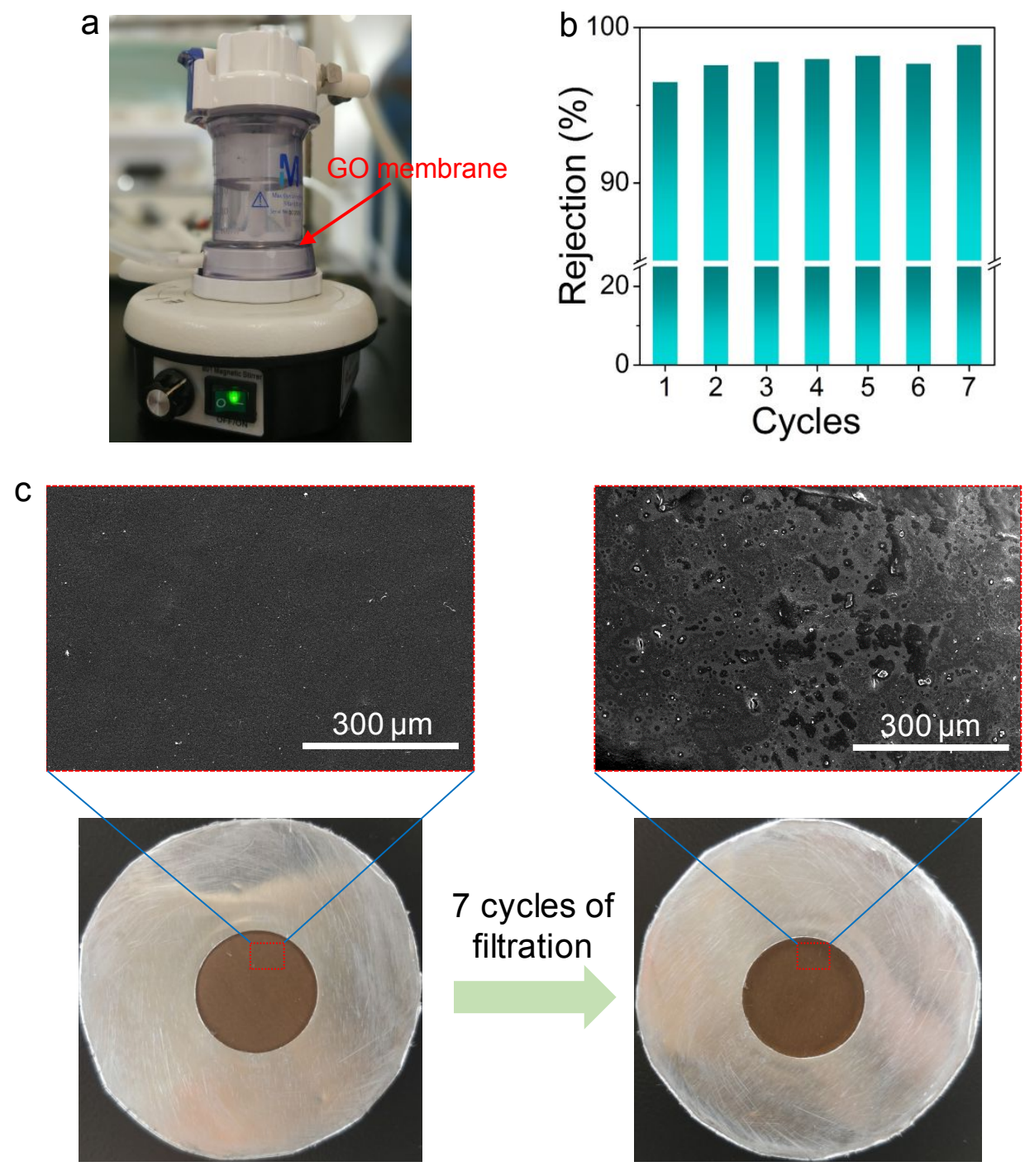

Figure S14. (a) The ultrafiltration cup used for the separation of the GO membranes. (b) Changes of the rejections for Cu-EDTA over 7 cycles. (c) Photographs and SEM observation on the surface of the ATPP@GOM-30 membranes before and after cycles of filtration. 


\section{References}

(1) Paeth, M.; Tyndall, S. B.; Chen, L.; Hong J.; Carson, W. P.; Liu, X.; Sun, X.; Liu, J.; Yang, K.; Hale, E. M. Csp ${ }^{3}-\mathrm{Csp}^{3}$ Bond-Forming Reductive Elimination from WellDefined Copper(III) Complexes. J. Am. Chem. Soc. 2019, 141, 3153-3159.

(2) Acik, M.; Lee, G.; Mattevi, C.; Chhowalla, M.; Cho, K.; Chabal, Y. J. Unusual infrared-absorption mechanism in thermally reduced graphene oxide. Nat. Mater. 2010, 9, 840-845.

(3) Litmanovich, A. D.; Plate, N. A. Alkaline hydrolysis of polyacrylonitrile. On the reaction mechanism. Macromol. Chem. Phys. 2000, 201, 2176-2180.

(4) Liu, J.; Sonshine, D. A.; Shervani, S.; Hurt, R. H. Controlled release of biologically active silver from nanosilver surfaces. ACS Nano 2010, 4, 6903-6913.

(5) Yang, Z.; Qian, J.; Yu, A.; Pan, B. Singlet oxygen mediated iron-based Fenton-like catalysis under nanoconfinement. P. Nati. Acad. Sci. U.S.A. 2019, 116, 6659-6664. 